\title{
An anatomical and osteometric study of the femoral sulcus angle in adult Malawians.
}

\author{
Anthony Mwakikunga ${ }^{1,2}$, Kondwani Katundu², Boniface Msamati ${ }^{3}$, \\ Anthony Gbenga Adefolaju ${ }^{4}$, Lynne Schepartz ${ }^{1}$
}

1. School of Anatomical Sciences, University of the Witwatersrand, Johannesburg, South Africa

2. Department of Anatomy, College of Medicine, University of Malawi, Blantyre, Malawi

3. Department of Anatomy, Hubert Kairuki Memorial University, Dar Es Salaam, Tanzania

4. Department of Preclinical Sciences, University of Limpopo, Sovenga, South Africa

\begin{abstract}
Background: Femoral sulcus angle is particularly important in clinical evaluation of patellofemoral joint. Individuals show considerable differences in asymmetrical dimensions of the femur.

Objectives: To determine the size of femoral sulcus angles in adult black Malawians using the skeletal collection in the department of Anatomy, College of Medicine and assess their gender differences; to compare femoral sulcus angles of Malawians with other ethnic groups.

Methods: A cross sectional study was done in which femoral sulcus angles of dry bones were measured using a goniometer.

Results: There is no significant difference in the mean sulcus angles between right and left femora in males $(p=0.8100)$ and females ( $p=0.0742)$; between all males combined and females combined $(p=0.8845)$. There is a significant difference in the mean between all left femora combined and all right femora combined $(\mathrm{p}=0.0260)$.

Conclusion: This study has provided the mean size of the femoral sulcus angle of adult Malawians. These findings suggest that the size of the sulcus angle cannot determine gender among adult black Malawians suggesting the interpretation that femora asymmetric dimensions are population specific, which should be considered in the patellofemoral joint evaluation.
\end{abstract}

Keywords: Femur, sulcus angle, patellofemoral joint

DOI: http://dx.doi.org/10.4314/ahs.v16i4.38

Cite as: Mwakikunga A, Katundu K, Msamati B, GbengaAdefolaju A, Schepartz. L. An anatomical and osteometric study of the femoral sulcus angle in adult Malawians. Afri Health Sci. 2016;16(4): 1182-1187. bttp:// dx.doi.org/10.4314/abs.v16i4.38

\section{Introduction}

The femoral trochlear groove is at the distal part of the femur. The sulcus angle is formed by joining two lines from the highest points on the medial and lateral condyles, which meet at the lowest point on the intercondylar groove ${ }^{1}$. This angle is particularly important in the clinical evaluation of the patellofemoral joint $t^{1,2}$.

\section{Corresponding author:}

Anthony Mwakikunga,

School of Anatomical Sciences,

University of the Witwatersrand Medical School,

7 York Road, Parktown 2193, Johannesburg, South

Africa

Phone: +27843917964

Email: mwakikungaanthony@gmail.com

African Health Sciences Vol 16 Issue 4, December, 2016
Although there has been evidence from the literature that the morphology of the femoral trochlear groove in fetuses is similar to that of adults ${ }^{3}$, individuals have been found to show considerable differences not only in the groove size, but also in all other asymmetrical dimensions of the femur ${ }^{4-6}$. The shape of the lower extremity of the femur is determined early in development, long before standing and walking ${ }^{7}$. During development, it has been demonstrated that the medial condyle is originally larger than the lateral one. It is because of the characteristic change in the position of the femur in adults and the establishment of extension of the knee during walking that the lateral condyle becomes larger than the medial one from about 3 years of age $\mathrm{e}^{3,8}$. Gender differences have also been related to hormonal and genetic factors, which affect the closure of epiphyseal plates ${ }^{9,10}$. Moreover, other morphometric studies have shown that there are gender and ethnic differences in the dimensions of the various parts of the femur ${ }^{11,12}$. Additional evidence from previous studies in Kenya ${ }^{10}$, South Africa ${ }^{4,5}$, Nigeria ${ }^{13}$, China ${ }^{6}$ and 
Malawi ${ }^{14-16}$ confirm that differences exist in the distal end of the femora. In light of the foregoing, it is clear that femoral dimensions and their characteristics might be population specific even within the same ethnic grouping and region. It was because of this that this study was designed to obtain baseline morphometric data for this population to determine the size of femoral sulcus angles in adult Malawians using the skeletal collection in the department of Anatomy, College of Medicine and assess their gender differences, and to compare femoral sulcus angles of Malawians with other ethnic groups.

\section{Methods}

A total of 196 completely fused femora of 64 males and
34 females, aged 21 - 82 years, were studied from the skeletal collection in the Department of Anatomy, College of Medicine, University of Malawi. All femora belonged to black Malawian population. The bones had already been categorized by sex and paired (for each individual) using their mass as well as other asymmetrical dimensions. Malformed and broken bones were excluded from the sample. Measurements of the length of the femur, heights of lateral and medial condyles, bicondylar width and depth of the groove were taken on an osteometric board using sliding calipers and rulers. The sulcus angle was directly measured on the femur using a goniometer. This method was adopted and modified from previous studies as shown in Figure ${ }^{17}$.

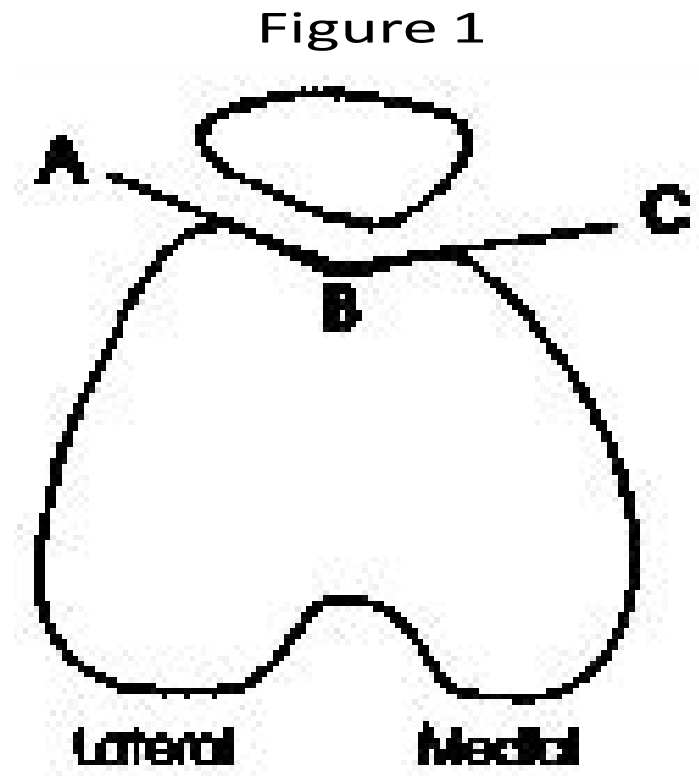

Figure 1: Method used to measure the sulcus angle. The sulcus angle was defined by lines joining the highest points of the medial and lateral condyles and the lowest point of the intercondylar groove $(\mathrm{AB}$ and $\mathrm{CB}$ ) as described earlier ${ }^{17}$. The angle $\mathrm{ABC}$ was then directly measured by a goniometer. All angle measurements were reported in degrees.

The study was conducted in accordance with the Anatomy Act No. 14 of 1990 and was approved by the University of Malawi's College of Medicine Research and Ethics Committee (COMREC) with a clearance number P02/10/872.

\section{Data analysis}

JMP10 (John's Macintosh Project) software (SAS Institute, Cary, NC, USA) was used for statistical comparisons of the means of the femoral sulcus angles of adult male and female black Malawians; mean sulcus angles of left and right male femora; left and right female femora; all males combined versus all females combined; all right combined versus all left combined using a one way ANOVA followed by Tukey-Kramer post hoc analysis in order to determine the size of the sulcus angles and assess their sexual differences if any; and also to compare the mean femoral sulcus angles of this population with other ethnic groups. Differences were considered statistically significant when $\mathrm{p}<0.05$.

\section{Results}

There was no significant difference in the mean sulcus angles between the right and left dry femora $(p=0.0844)$; all males combined and all females combined $(\mathrm{p}=0.8845)$. However, there was a significant difference in the mean sulcus angles between all left femora combined and all right femora combined $(p=0.0260)$ (tables 1 and 2).

African Health Sciences Vol 16 Issue 4, December, 2016 
Table 1: Comparison of means of the femoral sulcus angles of adult Malawian males and females

\begin{tabular}{lllll}
\hline Variable & Males & \multicolumn{3}{c}{ Females } \\
\cline { 2 - 5 } & Right & Left & Right & Left \\
Minimum & $144^{\circ}$ & $127^{\circ}$ & $135^{\circ}$ & $116^{\circ}$ \\
Maximum & $152^{\circ}$ & $157^{\circ}$ & $159^{\circ}$ & $149^{\circ}$ \\
Mean & $142.9^{\circ}$ & $141.8^{\circ}$ & $144.3^{\circ}$ & $140.6^{\circ}$ \\
SE & $0.9^{\circ}$ & $0.9^{\circ}$ & $1.1^{\circ}$ & $1.1^{\circ}$ \\
\hline
\end{tabular}

Table 2: A summary of the analysis of variance using a one way ANOVA test to determine changes in the mean sulcus angles between various femoral groups.

\begin{tabular}{|c|c|c|c|c|c|c|}
\hline Source & & $d f$ & $\begin{array}{l}\text { Sum of } \\
\text { squares }\end{array}$ & $\begin{array}{l}\text { Mean } \\
\text { square }\end{array}$ & $\begin{array}{l}\text { F- } \\
\text { Ratio }\end{array}$ & P-value \\
\hline \multirow{2}{*}{$\begin{array}{l}\text { Femoral sulcus angles male left } \\
\text { and right, female left and right }\end{array}$} & Group & 3 & 246.08 & 82.03 & 2.2539 & 0.0844 \\
\hline & Error & 152 & 5531.7 & 36.39 & & \\
\hline \multirow[t]{2}{*}{$\begin{array}{l}\text { All males combined versus all } \\
\text { females combined }\end{array}$} & Group & 1 & 0.7940 & 0.7940 & 0.0212 & 0.8845 \\
\hline & Error & 154 & 5777.01 & 37.51 & & \\
\hline \multirow{2}{*}{$\begin{array}{l}\text { All right combined versus all left } \\
\text { combined }\end{array}$} & Group & 1 & 183.51 & 183.52 & 5.052 & 0.0260 \\
\hline & Error & 154 & 5594.3 & 36.33 & & \\
\hline
\end{tabular}

Significant difference

As presented in table 3, there were also no significant differences between right males and right females; left males and

As presented in table 3, there were also no significant dif- and left females; right males and left males; all males comferences between right males and right females; left males bined and all females combined in Malawian population.

TABLE 3

\begin{tabular}{lccc}
\hline Variable & Means & P-value & Remarks \\
\hline Right males vs. right females & $142.9^{\circ} \mathrm{vs} 144.3^{\circ}$ & 0.7347 & $\mathrm{NS}$ \\
Left males vs. left females & $141.8^{\circ} \mathrm{vs} 140.6^{\circ}$ & 0.8465 & $\mathrm{NS}$ \\
Left males vs. right females & $141.8^{\circ} \mathrm{vs} 144.3^{\circ}$ & 0.2625 & $\mathrm{NS}$ \\
Left females vs. right males & $140.6^{\circ} \mathrm{vs} 142.9^{\circ}$ & 0.3688 & $\mathrm{NS}$ \\
Left males vs. right males & $141.8^{\circ} \mathrm{vs} 142.9^{\circ}$ & 0.8100 & $\mathrm{NS}$ \\
Left females vs. right females & $140.6^{\circ} \mathrm{vs} 144.3^{\circ}$ & 0.0742 & $\mathrm{NS}$ \\
All males combined vs. all females combined & $142.4^{\circ} \mathrm{vs} 142.5^{\circ}$ & 0.8845 & $\mathrm{NS}$ \\
& & & $\mathrm{S}$ \\
\hline
\end{tabular}

There were also no significant differences in the mean femoral sulcus angles between the current study and other studies as shown in Table 4. 
Table 4: Summary of comparison of means of the femoral sulcus

angles of the present study with other studies.

\begin{tabular}{llll}
\hline Variable & Mean & P-value & Remarks \\
\hline The present study, both genders combined & $142.4^{\circ}$ & & \\
Murshed et al., 2001 study, both genders combined & $141.7^{\circ}$ & $\geq 0.05$ & $\mathrm{NS}$ \\
Brattstrom et al., 1964 study, both genders & $142^{\circ}$ & $\geq 0.05$ & $\mathrm{NS}$ \\
Buard et al., 1981 study, both genders combined & $144^{\circ}$ & $\geq 0.05$ & $\mathrm{NS}$ \\
\hline NS = No significant difference & & & \\
\hline
\end{tabular}

NS $=$ No significant difference

\section{Discussion}

In this study, no significant difference was found in the mean femoral sulcus angles between males and females. In a similar study from Turkey conducted on 80 human dry femora and 100 magnetic resonance images (MRI) - 50 females, 50 males, Murshed et al reported no significant differences in the mean femoral sulcus angles between males and females ${ }^{18}$. Similarly, Nietosvaara, asserted that no significant difference in the mean sulcus angle was noted between sexes in a study of 100 knees of 25 boys and 25 girls $^{19}$. For this reason, observations of the present study suggest that the size of the sulcus angle cannot determine sex in Malawians. This supports earlier studies that have reported that sexual dimorphism is race and population specific $c^{10,14,20-23}$.

Additionally, it has been observed in our study that the mean femoral sulcus angles for males combined and females combined are $142.3^{\circ} \pm 0.8$ and $142.5^{\circ} \pm 0.8$ respectively. According to Brattstrom's and Buard's work, the means for both sexes were $142^{\circ}$ and $144^{\circ}$ respectively ${ }^{24,25}$. Besides that, Murshed et al have reported that the mean is $141.7^{\circ}$ if the right and left dry femora for both sexes are considered together ${ }^{18}$. These results are in agreement with those found in our study. Therefore, our finding does not only support Brattstrom's and Buard's work, but also extends those of other studies ${ }^{4,10,14,26}$, who established several correlations between various femoral dimensions in which the sulcus angle was not specifically addressed.

Furthermore, no significant differences were observed between left males and right males $(p=0.8100)$. Likewise, Murshed et al found similar results ( $\mathrm{p} \quad 0.05)^{18}$. Other studies also indicate that the sulcus angles are not correlated with age, between and within sexes ${ }^{27}$. Thus, the size of the angle cannot determine the side of the femur and gender of an individual.

However, a significant difference was observed in the mean sulcus angles between all right femora combined and all left femora combined $(p=0.0260)$. Although this evidence is in variance with the findings of other authors $^{18,27}$, it could be argued that adult Malawian females might be using their right limbs more than their left spontaneously, or this preference could be due to societal emphasis in using one limb more than the other based on the nature of physical activities in which they are involved if such activities really shape musculoskeletal systems as reported by others ${ }^{9,28,29}$.

As already noted, the mean sulcus angle of adult Malawians is $142.4^{0}$. This is in variance with other studies whose results are several degrees smaller ${ }^{30}$. Moreover, Mulligan and Jones applied 3 methods of radiographic projections to the 74 knees of cadavers and the mean sulcus angles were $138.6^{0}, 141.6^{0}$ and $137.4^{0}$ respectively ${ }^{31}$. The Turkish MRI measurement of the mean sulcus angle was $133.8^{18}$. This means that there are differences in the mean sulcus angles of different ethnic groups. These variations could not only be due to geographical, nutritional and genetic factors, but also different techniques and methodologies used to assess the angle.

It has been reported that dysplasia of the femoral trochlear groove is the most important etiological factor in recurrent patellar luxation ${ }^{24}$. Because the lateral femoral condyle is larger and projects farther interiorly than the medial condyle, the trochlear groove is thought to provide bony stability resisting laterally directed forces ${ }^{28}$. Although some authors ${ }^{3}$ have reported that the decreased 
depth of the intercondylar sulcus is a primary cause of lateralization of the patella, other investigators ${ }^{12}$ have hypothesized that abnormal patellar kinematics are a result of the patella resting above the trochlear groove. Moreover, other studies have indicated that the shape of the lateral femoral condyle and osteochondritis dissecans may be associated with the development of patellofemoral lesions which are higher in females than males ${ }^{32}$.

Earlier studies have shown that a deep patellar groove with a higher lateral lip has considerable functional significance related to posture and gait ${ }^{9}$. Moreover, the lateral trochlear inclination is an important determinant of patellar alignment in weight bearing ${ }^{33}$. This is directly related to the high bicondylar angle in humans, which explains why there is a high frequency of lateral patellar luxation in females than males. On the other hand, other investigators have suggested that the stability of the patella is more a function of the increased tension of both patellar and quadriceps tendons as the knee flexes, and not necessarily a function of the depth of the trochlear groove ${ }^{29}$. In other words, the stability of the patellar is multi-factorial. For example, lateral subluxation of the patella is not only associated with high bicondylar angles and low lateral patellar groove margins, but also the involvement of the vastus medialis. Variations in the development of the origin of this muscle are evidenced on the spiral line of the medial aspect of the linear aspera. Such differences may well reflect differences in the action of this muscle in the maintenance of patellar stability ${ }^{27}$.

\section{Conclusion}

The current study has provided the mean size of the distal femoral sulcus angle of adult Malawians. There are no significant gender differences in the size of the femoral sulcus angles. Asymmetric dimensions of the femur seem to be population specific, which may suggest the interpretation that this could be genetic, nutrition and varying life styles. Besides that, the different methodologies and equipment used to determine the distal femoral dimensions by different researchers could contribute to the variations in some parameters. This study is clinically important in determining the stability of patell-ofemoral joints.

\section{Conflict of interest}

None to declare.

\section{References}

1.Harbaugh CM, Wilson NA, Sheehan FT. Correlating femoral shape with patellar kinematics in patients with patellofemoral pain. J Orthop Res 2010; 28:865-872

2.Carrillon Y, Abidi H, Dejour D, Fantino O, Moyen B, Tran-Minh VA. Patellar instability: assessment on MR images by measuring the lateral trochlear inclination-initial experience. Radiology 2000; 216: 582-585

3. Tardieu C. Development of the human hind limb and its importance for the evolution of biopedalism. Evol Anthr 2010; 19: 174-186

4. Asala SA, Bidmos MA, Dayal MR. Discriminant function sexing of fragmentary femur of South African blacks. Forensic Sci Int 2004; 145(1): 25 - 29

5. Glard Y, Jouve J. L, et al., An anatomical and biometrical study of the femoral trochlear groove in the human fetus. J Anat 2005; 206: 411-413

6.Xu H, Zhou Y, Liu Q, Tang Q, Yin J. Femoral morphologic differences in subtypes of high developmental dislocation of the hip. Clin Orthop Relat Res 2010; 468: 3371-3376

7.Li D, Sakuma R, Vakili NA et al., Formation of proximal and anterior limb skeleton requires early function of Irx 3 and Irx 5 and is negatively regulated by Shh signaling. Dev Cell 2014; 29(2): 233-240

8. Tardieu C, Glard Y, Garron E et al., Relationship between formation of the femoral bicondylar angle and trochlear shape: independence of diaphyseal and epiphysealgrowth. Am J Phys Anthropol 2006; 130(4): 491-500 9. Emons J, Chagin AS, Savendahl L et al., Mechanisms of growth maturation and epiphyseal fusion. Horm Res Paediatr 2011; 75: 383-391

10. Koech AC. Morphometric study of the distal femur in adult Kenyans. Thesis 2005

11. Tardieu C, Trinkaus E. Early ontogeny of the human femoral bicondylar angle. Am J Phys Anthropol 1994; 95: 183-195

12. Rosenstein AD, Veazey B, Shephard D, Xu KT. Gender differences in the distal femur dimensions and variation patterns in relation to KTA component sizing. Orthopedics 2008; 31(7): 652

13. Gray D, Gardner E. Prenatal development of the human knee and superior tibiofibular joints. Am J Anat 1950; 86: 233-287

14. Igbigbi PS, Msamati BC. Sex determination from femoral head diameters in black Malawians. East Afri Med J 2000; 77(3): 147-151 
15. Igbigbi PS, Msamati BC, Ng'ambi TM. Intercondy shelf angle in adult black Malawian subjects. Clin Anat 2001; 14: 254-257

16. Igbigbi PS, Msamati BC. Tibiofemoral angle in Malawians. Am J Orthop 2002; 34(6): 291-294

17. Powers, C.M. Patellar kinematics, part II: The influence of the depth of the trochlear groove in subjects with and without patellofemoral pain. Phys Ther 2000; 80: 965973

18. Murshed KA, Ciceklbas AE, et al., Femoral sulcus angle measurement: An anatomical study of magnetic resonance images and dry bones. Turk J Med Sci 2001; 34: 165-169

19. Nietosvaara Y. The femoral sulcus in children: An ultrasonographic study. J. Bone Joint Surg 1994; 76-B: 807809

20. Mahfouz M, Fatah EA, Bowers LS, Scuderi G. Three-dimensional morphology of the knee reveals ethnic differences. Clin Orthop Relat Res 2012; 470(1): 172-185 21. Macho GA. Is sexual dimorphism in the femur a "population specific phenomenon"? Z Morphol Anthropol 1990; 78(2): 229-242

22. King CA, Iscan MY, Loth SR. Metric and comparative analysis of sexual dimorphism in the Thai femur. $J$ Forensic Sci 1998; 43(5): 954-958

23. Igbigbi PS, Sharrif M. The bicondylar angle of adult Malawians. Clin Anat 2005; 15(4): 293-296

24 . Brattstrom H. Shape of the intercondylar groove normally and in recurrent dislocation of the patella. Acta Orthop Scand 1964; 68: 85-138
25. Buard J, Benoit J, Lortat-Jacob A et al., Les trochlees femorales creuses. Rev Chir Orthop 1981; 67: 721-729

26. Nhoha PU. The collo-diaphyseal angle of the femur in adult Nigerians. Afr J Med Sci 1991; 20(1): 143-147

27. Yang B, Yu J, Zheng $Z$ et al., Comparative study of sex differences in distal femur morphology in osteoarthritic knees in a Chinese population. PLoS One 2014; 9(2): e89394

28. Hiwale DS. Influence of physical activity on musculoskeletal system. Arch Intern Med 2012; 172(5): 444-446 29. Farahmand F, Senavongse W, Amis AA. Quantitative study of quadriceps muscles and trochlear groove geometry related to instability of the patellofemoral joint. J Orthop Res 1998; 16: 136-143

30. Merchant AC. Patellofemoral disorders: Biomechanics, diagnosis and nonoperative treatment. Operative arthroscopy (Ed. McGinty JB) Raven Press. New York, 1991; pp: 261-275

31. Mulligan ME, Jones ED. Femoral sulcus angle measurements. Am J Orthop 1997; 26: 541-543

32. Kamei G, Adachi N, Deie M et al., Characteristic shape of the lateral femoral condyle in patients with osteochondritis dissecans accompanied by a discoid lateral meniscus. J Orthop Sci 2012; 17: 124-128

33. Teng HL, Chen YJ, Powers CM. Predictors of patellar alignment during weight bearing: an examination of patellar height and trochlear geometry. Knee 2014;21(1): 142-146

34. Barink M, Van de Groes S, et al., The trochlea is bilinear and oriented medially. Clin Orthod Relat Res 2003; 411: $288-295$ 